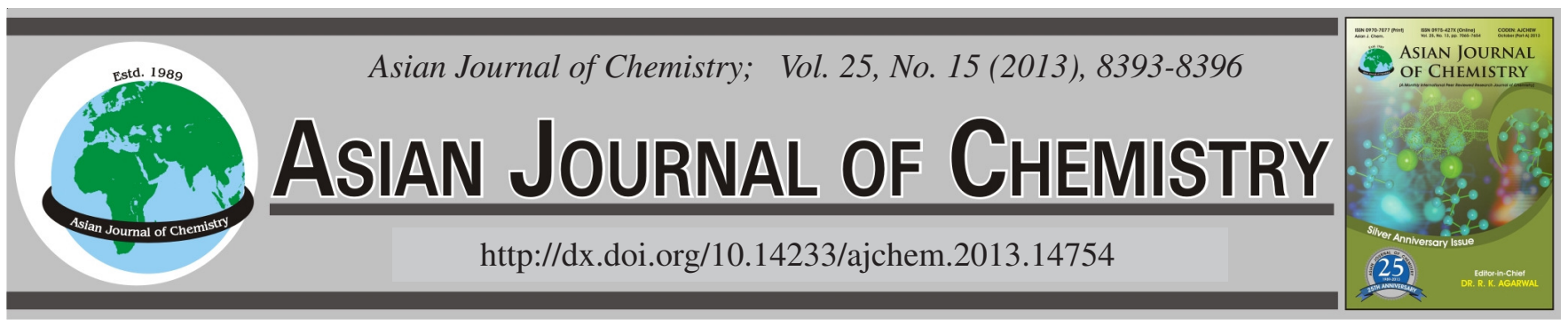

\title{
Synergistic Scale Inhibition Performance of Polyepoxysuccinic Acid with High-Voltage Electrostatic Field
}

\author{
Hai-Hua Li ${ }^{1,2, *}$, Zhen-Fa Liu ${ }^{1,2}$, Li-Hui Zhang ${ }^{1,2}$, Mei-Fang Yan ${ }^{1,2}$ and XiAo-Hui Li ${ }^{1,2}$
}

${ }^{1}$ Institute of Energy Resources, Hebei Academy of Science, Shijiazhuang 050081, Heibei Province, P.R. China

${ }^{2}$ Hebei Engineering Research Center for Water Saving in Industry, Shijiazhuang, Hebei, P.R. China

*Corresponding author: Fax: +86 311 83053046; Tel: +86 311 83017991; E-mail: c.t.0205@ sina.com

(Received: 1 November 2012;

Accepted: 21 August 2013)

AJC-13959

\begin{abstract}
In order to improve the scale inhibition effect of polyepoxysuccinic acid, a high-voltage electrostatic field was introduced to combine with polyepoxysuccinic acid in the water sample flowing through an electrostatic water treatment apparatus. The synergistic scale inhibition performance was investigated by the static and dynamic experiments and the $\mathrm{CaCO}_{3}$ deposits formed in the static experiments were analyzed by IR and SEM. The results showed that there existed obvious synergistic scale inhibition effect between polyepoxysuccinic acid and the electrostatic field. The efficiency of the scale inhibition of polyepoxysuccinic acid was improved by $18.9 \%$ in the static experiment and $14.5 \%$ in the dynamic experiment under the influence of the electrostatic field. The electrostatic field was in favour of the formation of aragonite and the synergism between polyepoxysuccinic acid and the electrostatic field distorted $\mathrm{CaCO}_{3}$ crystallite completely and made the $\mathrm{CaCO}_{3}$ deposit more dispersive which could be washed away by water flow easily.
\end{abstract}

Key Words: High-voltage electrostatic field, Polyepoxysuccinic acid, Scale inhibition, Synergism.

\section{INTRODUCTION}

Along with the environmental regulations being increasingly stringent, the waste including phosphorous has been limited in many countries. So the research and application of the green water treatment agents with low or without phosphor have become a research hotspot. In recent years, polyepoxysuccinic acid (PESA) as a no-phosphorus and biodegradable environmental friendly scale inhibitor has drawn more attention $^{1-5}$. But its scale inhibition performance is still worse than acrylic acid and maleic acid polymers in the practical application, especially when applied to the high-hardness water. For enhancing the scale inhibition performance of PESA, the usual method is to introduce groups with the function of scale inhibition to the side chain of PESA or other higher efficiency water treatment agents to combine with it ${ }^{6-8}$. Compared with the chemical agents, the physical water treatment methods can not bring about extra cost of production and pollution, so using these methods as the ones combing with PESA is a better choice.

The electrostatic water treatment technique is a new physical water treatment method developing in recent decades. In practice, this method is mainly applied to sludge dewatering, bactericide and algaecide. Previous research ${ }^{9-11}$ found that the electrostatic field, especially the high-voltage electrostatic field, can affect the alignment state of $\mathrm{H}_{2} \mathrm{O}$ molecules and the chemical bonds in the deposits formed in the aqueous solution and further change the crystal form of the scales to produce the 'soft-scale' that can be wash away by water flow.

In this paper, a high-voltage electrostatic field was introduced to combine with PESA in the water sample flowing through an electrostatic water treatment apparatus.

The influences of the synergism on the scale inhibition performance of PESA were investigated by the static and dynamic experiments and the structures of the $\mathrm{CaCO}_{3}$ deposits formed in the static experiments were analyzed by IR and SEM. This research will provide a basis for developing a new technique and technics of synergic treatment of industrial circulating water with chemical and physical water treatment techniques.

\section{EXPERIMENTAL}

Polyepoxysuccinic acid (concentration $40 \%$ ), $\mathrm{CaCl}_{2} \cdot 6 \mathrm{H}_{2} \mathrm{O}$ and $\mathrm{NaHCO}_{3}$ were used as received. The electrostatic water treatment apparatus was made up of two parts, a high-voltage DC power supply and a water treatment channels (Fig. 1).

The electrode was enwrapped by PTFE to insulate from water. The electrode and the shell of the channels connected 


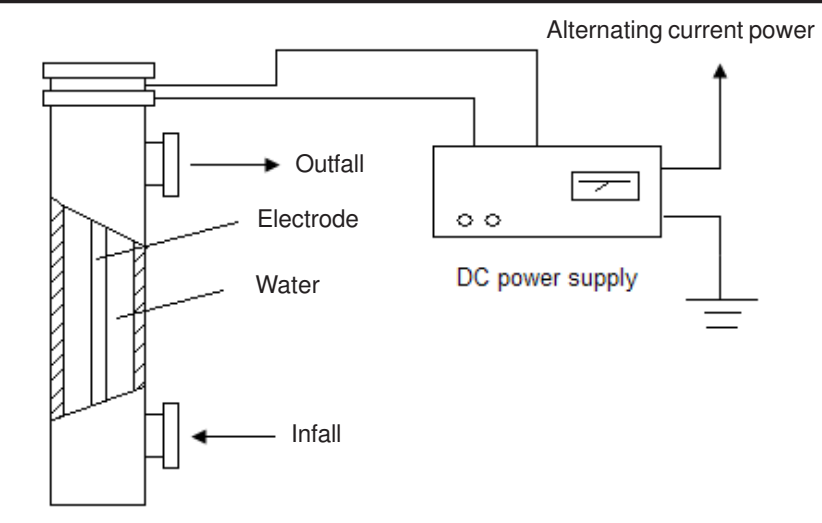

Water treatment channels

Fig. 1. Electrostatic water treatment apparatus

with the DC power supply by cables, so when adjusting the output voltage of the power supply, a positive electrostatic field produced around the electrode. The synergistic performances of PESA and the electrostatic field were investigated by static and dynamic experiments. Two kinds of water samples were used in the static experiments: the confecting water $(\mathrm{CW})$ and the electrostatic water $(\mathrm{EW})$. The confecting water with a certain concentration (as $\mathrm{CaCO}_{3}$ ) was prepared by dissolving $\mathrm{CaCl}_{2}$ and $\mathrm{NaHCO}_{3}$ with deionized water, $\mathrm{c}\left(\mathrm{Ca}^{2+}\right)=500 \mathrm{mg} / \mathrm{L}$, $\mathrm{c}\left(\mathrm{Ca}^{2+}\right): \mathrm{c}\left(\mathrm{HCO}_{3}^{-}\right)=1: 1$. The confecting water re-circulated through the electrostatic water treatment apparatus for $1 \mathrm{~h}$, electrostatic voltage $5000 \mathrm{~V}$, flow velocity $0.01 \mathrm{~m} / \mathrm{s}$, to get water sample named the electrostatic water (EW). A kind of groundwater was used in the dynamic experiment, which water quality was as follows: the concentration of $\mathrm{Ca}^{2+} 538 \mathrm{mg} / \mathrm{L}$ (as $\mathrm{CaCO}_{3}$ ); the concentration of $\mathrm{HCO}_{3}^{-} 313 \mathrm{mg} / \mathrm{L}\left(\right.$ as $\mathrm{CaCO}_{3}$ ); the total water hardness $735 \mathrm{mg} / \mathrm{L}$ (as $\mathrm{CaCO}_{3}$ ). The structures of the $\mathrm{CaCO}_{3}$ deposits formed in the static experiments were analyzed by IR and SEM.

\section{General procedure}

Static experiment: $500 \mathrm{~mL}$ water sample sealing in a conical flask was incubated at $80^{\circ} \mathrm{C}$ for $10 \mathrm{~h}$. The content of $\mathrm{Ca}^{2+}$ in the cooling and filtrating water was determined by EDTA titration. The efficiency of static scale inhibition, $\eta_{1}$, was calculated by formula (1).

$$
\eta_{1}=\frac{\mathrm{C}_{1}-\mathrm{C}_{0}}{\mathrm{C}_{2}-\mathrm{C}_{0}} \times 100 \%
$$

where $\mathrm{C}_{0}, \mathrm{C}_{1}$ and $\mathrm{C}_{2}$ represent the mass concentration of $\mathrm{Ca}^{2+}$ in the confecting water after heated, the confecting water with PESA or the electrostatic water with PESA after heated and the confecting water before heated, respectively, $\mathrm{mg} / \mathrm{L}$.

Dynamic experiment: The water treatment channels of the electrostatic water treatment apparatus connected to the circulating pipeline of the dynamic experiment apparatus. During the experiment, water flowed through the electrostatic field in the water treatment channels then to the heat exchanger of the dynamic experiment apparatus. In the process, the fouling produced and deposited on the surface of the heat exchanger. The fouling resistance of the heat exchanger and water, $R_{d}$, $\mathrm{m}^{2} \cdot \mathrm{K} / \mathrm{W}$, was calculated by formula (2).

$$
\mathrm{R}_{\mathrm{d}}=\frac{\mathrm{A}}{\mathrm{Q}}\left(\Delta \mathrm{T}_{\mathrm{md}}-\Delta \mathrm{T}_{\mathrm{mc}}\right)
$$

where $\mathrm{A}$ is the area of the heat exchanger, $\mathrm{m}^{2}$; $\mathrm{Q}$ is the rate of the heat transfer, $\mathrm{W} ; \Delta \mathrm{T}_{\mathrm{md}}$ is the average temperature difference between the heat exchanger covering with fouling and water, $\mathrm{K} ; \Delta \mathrm{T}_{\mathrm{mc}}$ is the average temperature difference between the heat exchanger without fouling and water, $\mathrm{K}$.

The rate of dynamic scale inhibition $\eta_{2}$ was calculated by formula (3).

$$
\eta_{2}=\left(1-\frac{\mathrm{R}_{\mathrm{d}^{\prime}}}{\mathrm{R}_{\mathrm{d}}}\right) \times 100 \%
$$

where $R_{d^{\prime}}$ is the fouling resistance of the groundwater with PESA or electrostatic groundwater with PESA, $\mathrm{m}^{2} \mathrm{~K} / \mathrm{W} ; \mathrm{R}_{\mathrm{d}}$ is the fouling resistance of the groundwater, $\mathrm{m}^{2} \cdot \mathrm{K} / \mathrm{W}$.

Detection method: The $\mathrm{CaCO}_{3}$ deposits formed in the static experiments were collected on fresh microscope slides at the bottom of the flasks and dried at $40{ }^{\circ} \mathrm{C}$. Using China KYKY-2800B scanning electron microscope analyzed the morphology of scales. The slides after spraying gold were pasted on the sample desk and observed by SEM under the condition of acceleration voltage $20 \mathrm{kV}$ and amplified factor 1500 .

The crystal form of the $\mathrm{CaCO}_{3}$ deposit was characterized by using USA Perkin-Elmer SP100 infrared spectrum spectrum, wave number $4000-400 \mathrm{~cm}^{-1}$.

\section{RESULTS AND DISCUSSION}

Fig. 2 showed the performance of chelating $\mathrm{Ca}^{2+}$ ion (the efficiency of static scale inhibition) of PESA in the electrostatic water $(\mathrm{EW}+\mathrm{P})$ could be improved compared with that in the confecting water $(\mathrm{CW}+\mathrm{P})$, the efficiencies of static scale inhibition could be increased about $20 \%$ in the experimental region before $\mathrm{EW}+\mathrm{P}$ reached $100 \%$. The result showed that there existed obvious synergistic scale inhibition effect between PESA and the electrostatic field.

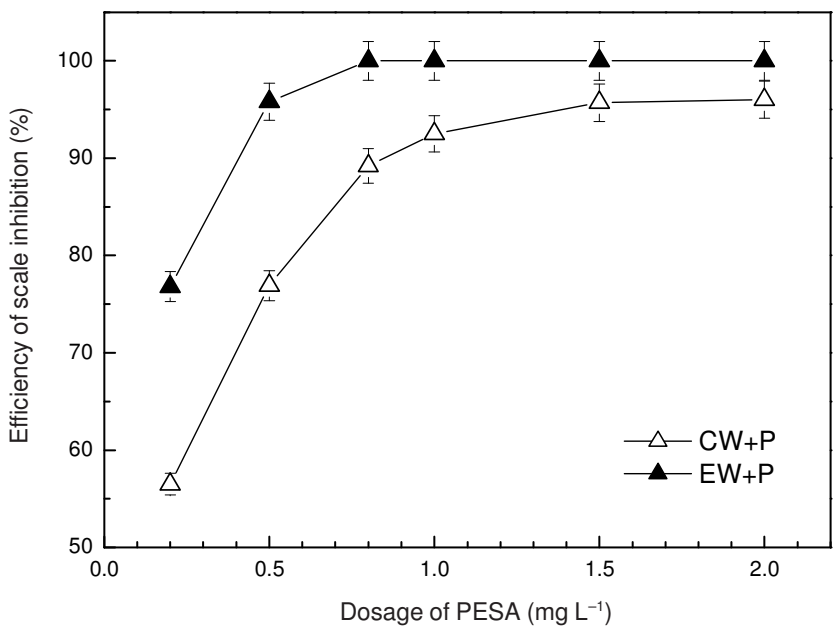

Fig. 2. Relation between PESA dosage and the static scale inhibition efficiency

The changes of the scale inhibition efficiency of PESA with temperature were evaluated and the results were shown in Fig. 3.

Fig. 3 showed under PESA $0.5 \mathrm{mg} / \mathrm{L}$ and $60^{\circ} \mathrm{C}$, the scale inhibition efficiency of PESA could reach $100 \%$ even in the 


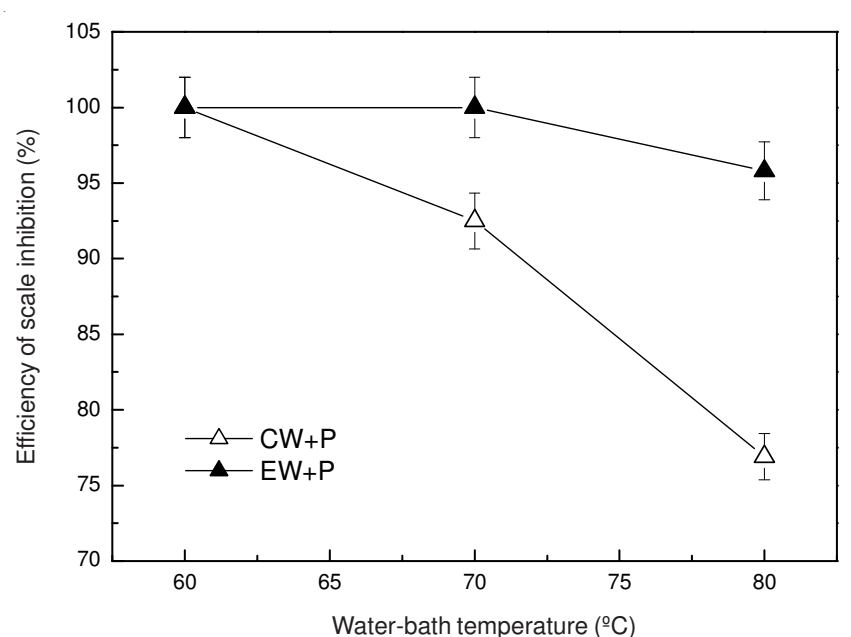

Fig. 3. Relation between the water-bath temperature and the static scale inhibition efficiency

confecting water. But with temperature increasing, the difference between the two water samples became visible. In the experimental range, $\mathrm{EW}+\mathrm{P}$ was affected by temperature much less than $\mathrm{CW}+\mathrm{P}$ that illuminated that the synergistic effect of PESA and the electostatic field exist in wide temperature range. Result of the dynamic experiment: The results of the dynamic experiments were shown in Fig. 4, which revealed that the fouling resistances of the groundwater with PESA and the electrostatic water with PESA all reduced significantly compared with that of the groundwater.

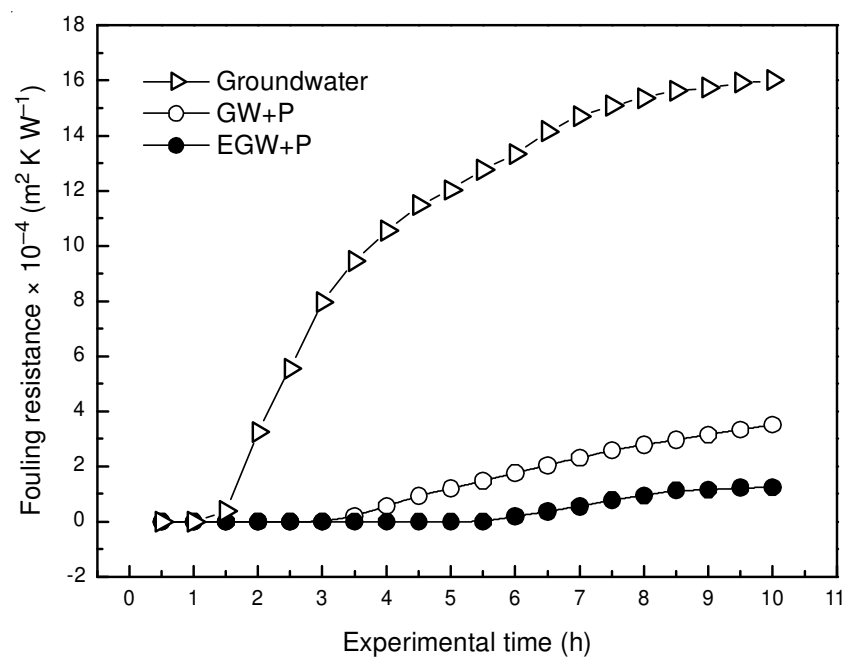

Fig. 4. Relation between the fouling resistance and the experimental time

Circulating at $40{ }^{\circ} \mathrm{C}$ for $10 \mathrm{~h}$, the fouling resistances of the groundwater, the groundwater with PESA $(\mathrm{GW}+\mathrm{P})$ and the electrostatic groundwater with PESA $(\mathrm{EGW}+\mathrm{P})$ were 15.73 $\times 10^{-4}, 3.52 \times 10^{-4}$ and $1.24 \times 10^{-4} \mathrm{~m}^{2} \mathrm{~K} / \mathrm{W}$, respectively. Calculated by the fouling resistance, the dynamic scale inhibition efficiency of PESA in the electrostatic groundwater was $92.1 \%$ that was $14.5 \%$ higher than that of PESA in the groundwater.

IR spectra: Fig. 5 showed the IR spectra of $\mathrm{CaCO}_{3}$ deposits formed in different water samples. 701 and $852 \mathrm{~cm}^{-1}$ peaks appearing in (b) were the absorption peaks of aragonite that revealed a part of $\mathrm{CaCO}_{3}$ crystals transformed from calcite to aragonite after treating by the electrostatic field. The absorption

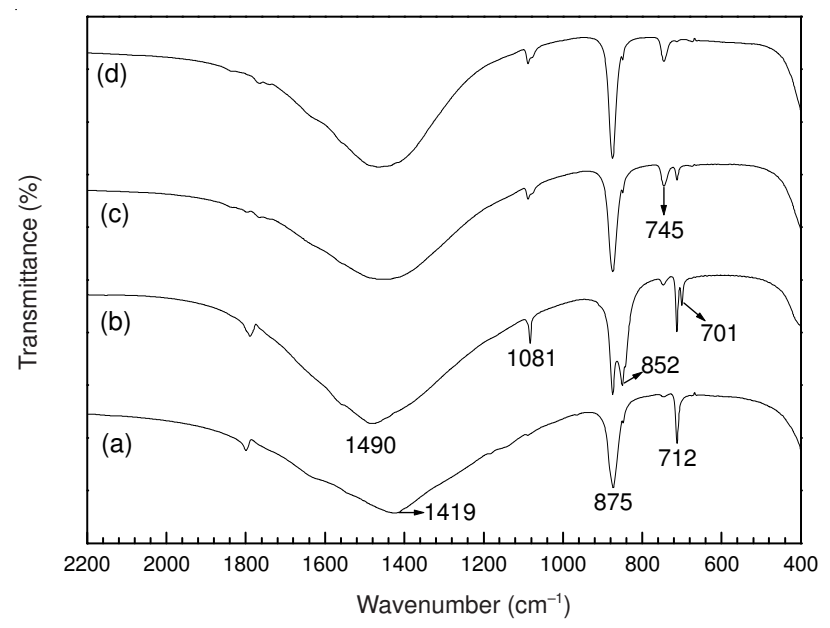

Fig. 5. IR spectrograms of the $\mathrm{CaCO}_{3}$ deposit formed in the different water samples. a-the confecting water; b-the electrostatic water; $\mathrm{c}-\mathrm{CW}+\mathrm{P}$; $\mathrm{d}-\mathrm{EW}+\mathrm{P}$

peaks in (c) belonged to vaterite except the weak peak of calcite at $712 \mathrm{~cm}^{-1}$, while in (d) even this peak of calcite also disappeared. The result showed PESA could transformed almost all calcite and aragonite into vaterite, while the synergism of PESA and the electrostatic field intensified this transformation further.

Results of SEM: SEM micrographs of the $\mathrm{CaCO}_{3}$ deposit formed in the confecting water $(\mathrm{CW})$ and the electrostatic water (EW) were shown in Fig. 6. The $\mathrm{CaCO}_{3}$ deposit formed in confecting water $(\mathrm{CW})$ (showed in a) were composed of the rhombohedral (the typical morphology of calcite crystallites) and a small quantity of petaliform particles. Under the influence of the high-voltage electrostatic field, a part of the $\mathrm{CaCO}_{3}$ deposit transformed into the cluster-like particles (the typical morphology of aragonite crystallite) just as shown in (b) that conformed to the result of IR and the sizes of the rhombohedral particles decreased obviously. The results of IR and SEM both proved the appearance of aragonite in the $\mathrm{CaCO}_{3}$ deposit formed in the electrostatic water that showed the electrostatic field is advantageous of the formation of aragonite crystals. The reason may be that $\mathrm{HCO}_{3}{ }^{-}$ions and $\mathrm{H}_{2} \mathrm{O}$ molecules are induced by the high-voltage positive electrostatic field and their polarity are enhanced when water flowed through the water treatment channels. The active $\mathrm{HCO}_{3}{ }^{-}$ion combines with $\mathrm{Ca}^{2+}$ ion to form $\mathrm{CaCO}_{3}$ crystal nucleus more easily, at the same time, the active $\mathrm{H}_{2} \mathrm{O}$ molecules adsorb on the newly generated nuclei immediately to make them exist steadily or form much finer particles to disperse evenly in the aqueous solution. The effects of the electrostatic field on anions and $\mathrm{H}_{2} \mathrm{O}$ molecules increase the dipole moment and solubility product of formed $\mathrm{CaCO}_{3}$, further increase the free energy of $\mathrm{CaCO}_{3}$ crystallization process. Because the solubility product and free energy of aragonite is higher, the $\mathrm{CaCO}_{3}$ deposits are prone to form aragonite rather than calcite in the elcetrostatic water.

Fig. 7 showed the $\mathrm{CaCO}_{3}$ deposits formed in the water samples containing PESA, which illuminated that the morphology of the $\mathrm{CaCO}_{3}$ deposit was distorted completely and the crystal form changed from calcite (the rhombohedral particles) to vaterite (the plate-shaped particles). This is mainly because PESA can ionize in the aqueous solution to produce the long- 


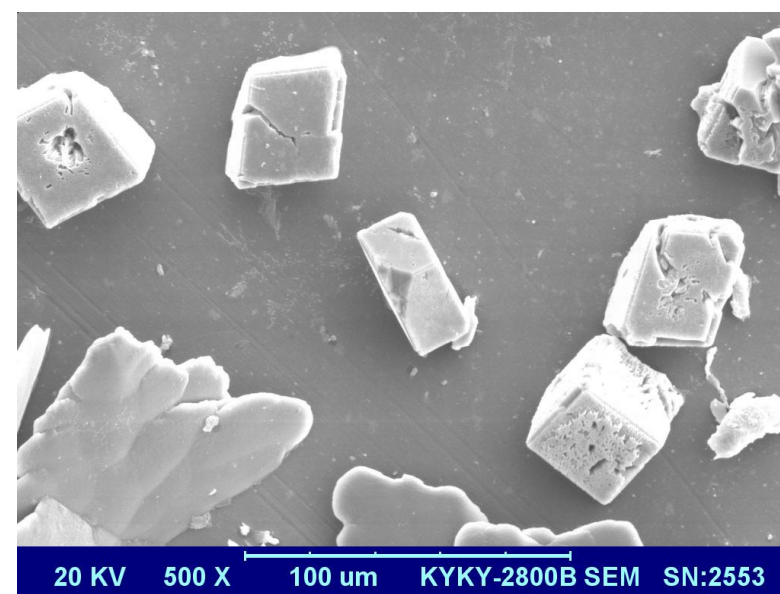

(a) Micrograph of $\mathrm{CaCO}_{3}$ formed in the confecting water

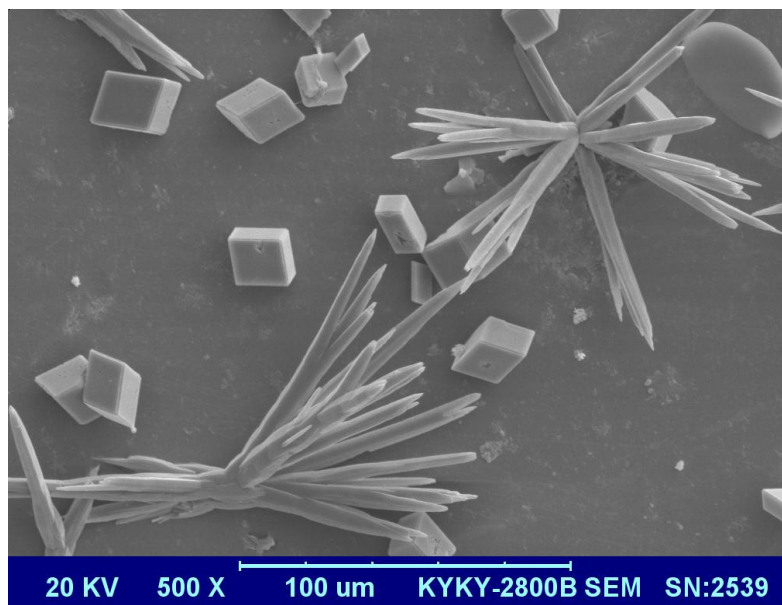

(b) Micrograph of $\mathrm{CaCO}_{3}$ formed in the electrostatic water

Fig. 6. SEM micrographs of $\mathrm{CaCO}_{3}$ deposit formed in $\mathrm{CW}$ and $\mathrm{EW}$

chains bearing lots of negative charges. The chains can not only chelate $\mathrm{Ca}^{2+}$ in the solution to decrease the probability of forming $\mathrm{CaCO}_{3}$ deposition, but also adsorb on the active growing points of $\mathrm{CaCO}_{3}$ crystal grains to prevent the formation of the regular crystals. After water treated by the electrostatic field, the crystallites were smoother compared with that in (a) and the beam-like particles in (a) disappeared. The deposits accumulated by the crystallites were more dispersive and more removable that could be washed away by water flow easily.

\section{Conclusion}

In this paper, we studied the influence of the electrostatic field on the scale inhibition performance of PESA by using the static and dynamic experiments. In the static experiments, under $\mathrm{Ca}^{2+} 500 \mathrm{mg} / \mathrm{L}, \mathrm{HCO}_{3}{ }^{-} 500 \mathrm{mg} / \mathrm{L}$ and PESA $0.5 \mathrm{mg} / \mathrm{L}$, the scale inhibition efficiency of PESA was increased $18.9 \%$ in the electrostatic water and in the dynamic experiment the percentage of increase was $14.5 \%$. The results of IR and SEM indicated that the electrostatic field was in favour of the formation of aragonite and the synergism between PESA and the electrostatic field could distort $\mathrm{CaCO}_{3}$ crystallite more remarkably and translated the crystal forms from calcite and aragonite to vaterite. The deposits got more slippery and dispersive compared with that formed in the confecting water with PESA and easily washed away by water flow.

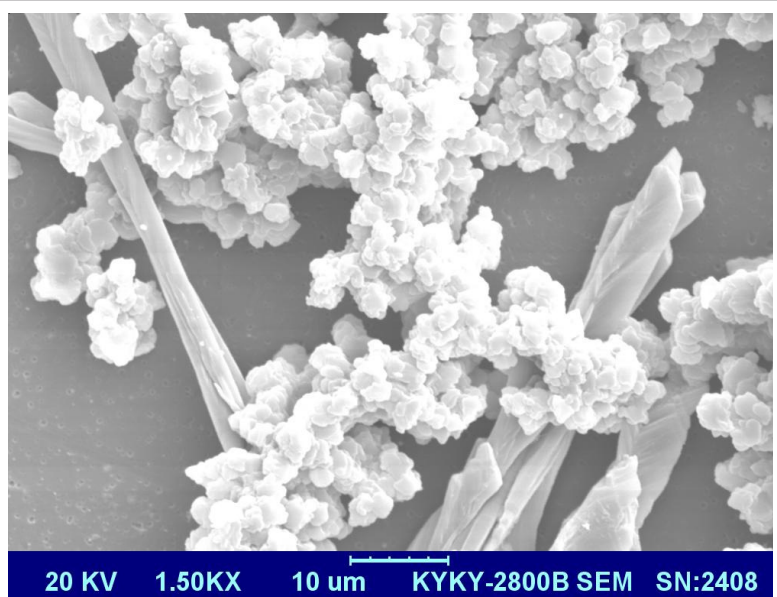

(a) Micrograph of $\mathrm{CaCO}_{3}$ formed in $\mathrm{CW}+\mathrm{P}$

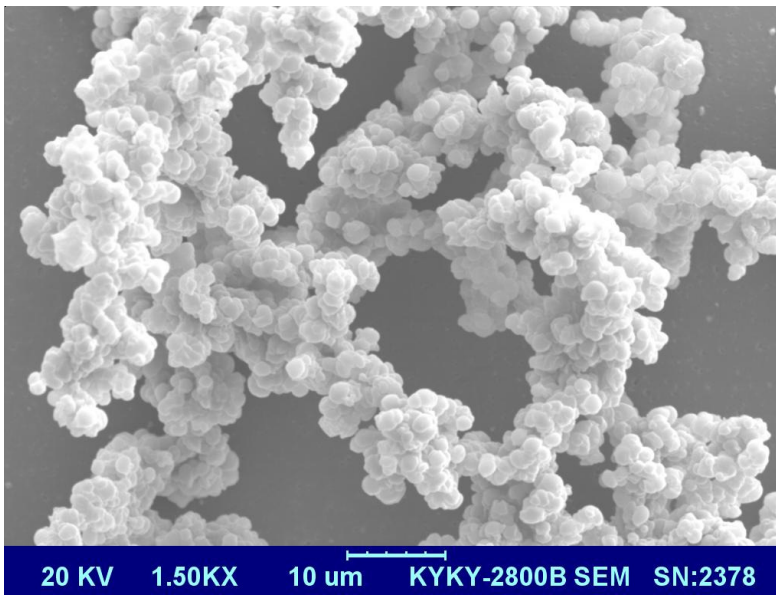

(b) Micrograph of $\mathrm{CaCO}_{3}$ formed in $\mathrm{EW}+\mathrm{P}$

Fig. 7. SEM micrographs of $\mathrm{CaCO}_{3}$ deposit formed in $\mathrm{CW}+\mathrm{P}$ and $\mathrm{EW}+\mathrm{P}$

\section{ACKNOWLEDGEMENTS}

The work is mainly supported by the Natural Science Foundation of Hebei (B2010001558, B2011302001 and 13254006D).

\section{REFERENCES}

1. J.M. Brown, J.F. McDowell and K.T. Chang, US Patent 5062962 (1991).

2. J.M. Brown and J.F. McDowell, US Patent 5147555 (1992).

3. W.C. Ehrhardt, US Patent 6585933 (2003).

4. R.Ch. Xiong, Q. Zhou and G. Wei, Chin. Chem. Lett., 14, 955 (2003).

5. D. Liu, W.B. Dong, F.T. Li, F. Hui and J. Lédion, Desalination, 304, 1 (2012).

6. D.F. Zidoves and P.M. Prabhu, US Patent 5562830 (1996).

7. M.K. Fader, D.T. Nguyen, H.W. Xiang, F. Zhang and T.F. Ling, US Patent 6355214 (2002).

8. B.R. Zhang, P.D. Sun, F. Chen and F.T. Li, Colloid. Surf. A, 410, 159 (2012).

9. W.A. Barton, S.A. Miller and C.J. Veal, Drying Technol., 17, 497 (1999).

10. S.H. Lee, A Study of Physical Water Treatment Technology to Mitigate the Mineral Fouling in a Heat Exchanger, Drexel University, Michigan, USA (2002).

11. Y.I. Cho, A.F. Fridman, S.H. Lee and W.T. Kim, Adv. Heat Transfer, 38, 1 (2004). 